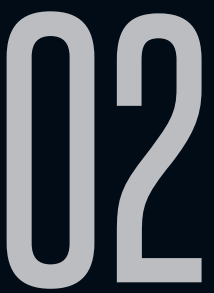

\title{
“METZENGERSTEIN" DE POE NA GRANDE TELA
}

Maria da Luz Alves Pereira (CMCG)

Recebido em $11 \mathrm{fev}$ 2018. Maria da Luz Alves Pereira é Doutora é em Letras Aprovado em 08 mai 2018. pela Universidade Presbiteriana Mackenzie (UPM) e docente em Língua Inglesa no Colégio Militar de Campo Grande (CMCG). Como pesquisadora, atua principalmente nos seguintes temas: tradução, adaptação, intermidialidade, cinema, gótico e dialogismo. Com ativa produção, vale destacar algumas publicações em periódicos: "Toby Dammit a partir do olhar de Fellini", em Todas as Letras (2017), "O moderno e o contemporâneo: relações dialógicas entre Poe e Vilela", em Acta Scientiarum. Language and Culture (Impresso) (2015) e "O retrato oval a partir do olhar de Poly Bernatene" em SOLETRAS (2012). Atualmente, é integrante do grupo de pesquisa "Estudos da Intermidialidade: teorias e ensino", sob a coordenação da profa $\underline{\text { a }}$ a a Aurora Gedra Ruiz Alvarez. Lattes: http://buscatextual.cnpq.br/buscatextual/ visualizacv.do?id=K4239403U1. E-mail: daluz_alves@ hotmail.com

Resumo: Muito se tem discutido acerca do Gótico, principalmente sobre as razões que fazem desse gênero uma manifestação cultural plenamente adaptável e renovável, que perdura por séculos. Diante do exposto, o presente artigo visa discutir o Gótico e suas principais estratégias de representação. Para desenvolver essa discussão, realiza-se a análise 
do conto "Metzengerstein", de Edgar Allan Poe, e da adaptação fílmica homônima, dirigida por Roger Vadim. O referencial teórico recai sobre estudos literários que abarcam a temática proposta, incluindo nomes como Fred Botting, David Punter, H. P. Lovecraft, Stephen King, Wolfgang Kayser e Victor Hugo.

Palavras-chave: Cinema; Conto; Grotesco; Horror; Terror.

Abstract: A lot has been discussed about the Gothic, especially on the reasons that make the genre a totally adaptable and renewable cultural manifestation, which lasts for centuries. In view of the above, this article aims to discuss the Gothic and its main strategies of representation. To develop this discussion, it analyzes the short story "Metzengerstein" by Edgar Allan Poe and the homonymous film adaptation directed by Roger Vadim. The theoretical reference is based on literary studies that cover the proposed theme, including names such as Fred Botting, David Punter, H. P. Lovecraft, Stephen King, Wolfgang Kayser and Victor Hugo.

Keywords: Cinema; Grotesque; Horror; Short story; Terror.

Se em muitas das minhas produções o terror tem sido a tese, afirmo que não é o terror da Alemanha, mas da alma, - eu deduzi este terror de sua fonte legítima, e exotei-o a seus resultados legítimos. ${ }^{1}$ (Edgar Allan Poe) $)^{2}$

Escritor americano, que embora tenha lutado para deixar um legado como poeta, Edgar Allan Poe (1809-49) ficou mais conhecido por ser um grande contador de histórias de terror, de mistério e de

1 If in many of my productions terror has been the thesis, I maintain that terror is not of Germany, but of the soul, - that I have deduced this terror only from its legitimate source, and urged it only to its legitimate results.

2 Todas as traduções deste trabalho são de nossa autoria. Para realizar tal tarefa, procuramos nos manter mais próximos do texto fonte, visando restituir o seu sentido, mesmo que para isso, em alguns casos, fosse necessário recorrer a uma tradução literal. 
morte. Nesse campo, iniciou sua carreira literária com a publicação de Tamerlane and other poems (1827) e "Metzengerstein" (1832), a sua primeira experiência na prosa. Nessas obras, ele já dava sinais de sua veia gótica, mostrando a sua predileção pelo horror natural, pelos estados mentais obsessivos e pela investigação dos extremos da natureza humana, tendendo a uma inquestionável influência no desenvolvimento da vertente do Gótico psicológico, distinguindo sua ficção do horror sobrenatural presente em Walpole, Lee, Radcliffe, Schiller ou Lewis. Seus contos policiais ou histórias de detetive, como as conhecemos agora, assim como suas experiências com a ficção científica, são de fato resultado de seu "goticismo experimental"3 (FISHER, 2009, p.71), que o encaminhou para um Gótico que era só seu.

Para melhor situar Poe nesse cenário, este artigo propõe uma leitura do conto "Metzengerstein" e do segmento ${ }^{4}$ homônimo. Esse média-metragem, dirigido por Roger Vadim (1928-2000), é parte integrante do filme franco-italiano Histoires extraordinaires, em cores, com 121 minutos de duração, produzido por Cocinor, Les Films Marceau e Produzioni Europee Associati (PEA), lançado em 17 de maio de 1968, na França. Estamos utilizando a edição brasileira Histórias extraordinárias (2003).

Considerando que um embasamento a respeito do Gótico nos dá alicerce para a construção da análise proposta, iniciamos com uma reflexão acerca do termo, que inclui um exame do seu uso nos séculos XVIII, XIX e XX. Em seguida, possibilitamos uma discussão

3 Experimental Gothicism.

4 Para designar cada uma das três partes (médias-metragens) do filme, Don G. Smith (2003) utiliza o termo "segmento". Seguindo seus passos, adotamos a mesma terminologia e, de maneira similar, usamos itálico quando se refere ao filme e aspas com relação ao segmento. 
sobre suas principais estratégias de representação, o terror, o horror e o grotesco, como recursos de sua expressão. A fundamentação teórica desta seção é amparada por estudiosos da área como $\mathrm{H}$. P. Lovecraft (2007), Stephen King (1983), Wolfgang Kayser (2003) e Victor Hugo (2010) entre outros.

Afinal, o que é o Gótico? Quais as origens e as características desse gênero relativamente novo, se comparado aos clássicos, que remontam à Antiguidade Clássica e perduram até hoje, exercendo influências culturais nas mais diversas manifestações artísticas? Segundo o Etymology Dictionary, o termo Gótico diz respeito aos Godos, povo germânico que viveu na Europa Oriental por volta dos anos 100d.C., e vem a significar "bárbaro", "rude" e "cruel". Conforme o Dictionary of literature (1995, p. 92-93), o romance gótico é

um tipo de romance que foi muito popular no final do século XVIII, combinando elementos do sobrenatural, macabro ou fantástico, frequentes nos ambientes selvagens de Radcliffe, por exemplo, abadias em ruínas e castelos antigos. Os heróis e/ ou heroínas, quer medievais ou modernos, em sua maioria falam uma linguagem formal, curiosamente em desacordo (para o leitor moderno) com as situações deploráveis em que se encontram. 0 castelo de Otranto (1764), de Horace Walpole, e Os mistérios de Udolfo (1794), de Ann Radcliffe, estão entre os mais conhecidos exemplos do gênero. ${ }^{5}$

5 A type of novel that was enormously popular in the late 18th century, combining elementsof the supernatural, macabre or fantastic, often in wildly Radcliffe settings, e.g. ruined abbeys or ancient castles. The heroes and/or heroines, whether medievalor modern, for the most part speak in a formal, stilted language curiously at odds (for the modern reader) with the appalling situations they find themselves in. Horace Walpole's The castle of Otranto (1764) and Ann Radcliffe's The mysteries of Udolpho (1794) are among the best-known examples of the genre. 
Outra opinião é ainda oportuna. Jerrold E. Hogle (2011, 2011, p. 02) escreve que

uma história gótica geralmente ocorre (pelo menos por algum tempo) em um espaço arcaico ou aparentemente arcaico - seja um castelo, um palácio afastado, uma abadia, uma vasta prisão, uma cripta subterrânea, um cemitério, uma fronteira ou ilha primitiva, um casarão ou teatro antigos, uma cidade envelhecida ou submundo urbano, um armazém, uma fábrica, um laboratório ou edifício público decadentes, ou alguma nova recriação de um local ultrapassado, como um escritório com arquivos antigos, uma nave espacial obsoleta, ou uma memória de computador. ${ }^{6}$

Privilegiando uma abordagem histórica, a definição do dicionário aponta para a popularidade da literatura gótica nos fins do século XVIII indicando O castelo de Otranto de Horace Walpole (1717-97), como o primeiro romance gótico, publicado em 1764. Ambas as concepções ressaltam a categoria espacial como uma importante característica da narrativa gótica. Enquanto a primeira é específica, restringindo esses espaços a castelos e casarões antigos, a segunda faz um apanhado mais abrangente dos mesmos, abarcando desde o clássico castelo medieval até ambientes modernos, como naves em desuso ou recintos cibernéticos.

Essa inconstância reflete a imprecisão dominante em torno da expressão. Em consonância com os entendimentos anteriores, E. J.

6 a Gothic tale usually takes place (at least some of the time) in an antiquated or seemingly antiquated space - be it a castle, a foreign palace, an abbey, a vast prison, a subterranean crypt, a graveyard, a primeval frontier or island, a large old house or theatre, an aging city or urban underworld, a decaying storehouse, factory, laboratory, public building, or some new recreation of an older venue, such as an office with old filing cabinets, an overworked spaceship, or a computer memory. 
Clery (2011) indica que nessa época o Gótico significava qualquer coisa velha, fora de moda, vigorando a visão de que a era gótica foi um tempo de barbarismo, superstição e anarquia, percorrendo um período que vai do século $\mathrm{V}$ depois de Cristo, quando os invasores visigodos precipitaram a queda do Império Romano até a Renascença e a restauração da era clássica. No contexto britânico, estendeu-se até a reforma no século XVI.

Essa constatação nos leva a crer que ainda no século XIX, o Gótico está associado à ideia de estilo de arte medieval, de objeto obsoleto e, portanto, os escritores não queriam ter as suas ficções a ela vinculadas. O próprio Poe teve a recepção de suas obras avariadas por ter suas narrativas ligadas a cenários arcaicos e ambientes noturnos. Benjamin Fisher (2002) escreve que ao começar a atrair atenção por volta de 1835, publicando suas histórias macabras no Southern Literary Messenger, os críticos teciam notas negativas a respeito de seu "germanismo" (o que hoje chamamos de Gótico) e lamentavam o desperdício de seu talento, apontando a sua ficção como antiquada, sem erudição e bom gosto.

Não obstante, Poe não se rende aos comentários e fala explicitamente para si mesmo e implicitamente para muitos outros escritores góticos, quando no "Prefácio" de sua coleção de contos, Tales of the grotesque and arabesque (1840), rebate as acusações dirigidas a ele. Sua declaração, tomada como epígrafe deste artigo, além de conter a sua defesa, é expressão da ideia que ele tem do próprio estilo ao afirmar que o seu terror não é o da Alemanha, mas da "alma". A sua segurança é tamanha que chega a afrontar os críticos, desafiando-os a reconhecer em qualquer dos contos ali publicados características da referida espécie de "germanismo" 
que ele chama "pseudo-horror" (POE, 1996, p.129). Analisando o teor de seu pronunciamento, Fisher (2009, p.67) diz que, em outras palavras, "Poe explorava o terror onde ele se originava e funcionava: na mente. Sua mente assombrada revela muito mais arte do que fazem outros góticos em suas histórias, onde o pilar é uma emoção pura no nível do intestino". 7 A categorização de obras desse período como góticas como conhecemos hoje, incluindo as de Poe, data do século seguinte. Clery (2011, p.21) atesta que “o 'romance gótico' é, assim, especialmente, uma cunhagem do século $X X^{\prime \prime}{ }^{8}$

Para podermos vislumbrar a transposição do goticismo de Poe em linguagem cinematográfica, examinemos as principais estratégias de representação do Gótico, iniciando pelo terror. Estudando o horror sobrenatural na literatura, Lovecraft (2007) concebe que o terror nasce da capacidade de imaginação, e que o seu efeito (realização) no espectador ou leitor requer dele uma capacidade de distanciamento da vida cotidiana, ou seja, é necessário que esse receptor esteja livre dos eventos ordinários e consiga se isolar do mundo externo, emergindo nesse recinto restrito do macabro espectral.

Por isso, as histórias de costume que trazem acontecimentos diários com relatos comuns são sempre do agrado e tem boa recepção junto ao público, não correndo risco os produtores e editores que investem nesse tipo de produto, pois o lucro é garantido. Essa circunstância é justificada pelo fato de que, não tendo um caráter nada em particular, não necessitando de um distanciamento, essas

7 Poe explored terror where it originated and functioned: in the mind. His haunted minds reveal far more art than do those in many another gothic tale where the mainstay is a thrill at sheer gut level.

8 The 'Gothic novel' is thus mostly a twentieth-century coinage. 
produções estão mais próximas da natureza humana e não chocam. Pensando assim, como as histórias de terror e horror conseguem se manter atraentes e permanecer vivas? A resposta não é de todo incompreensível: há sempre alguém desejoso de fugir da rotina, com instinto de libertação da normalidade, propenso a se sujeitar a experimentar outras emoções que não as que lhe são familiares.

Discorrendo a respeito das emoções dos povos primitivos, Lovecraft (2007, p.13) diz que os primeiros instintos foram a sua resposta ao ambiente no qual viviam. Ele explica que, envolvendo os fenômenos cujas causas e efeitos eram compreendidos, estavam o prazer e a dor; e o medo e o pavor rodeavam aqueles para os quais não achavam explicação, levando a interpretações fabulosas. Dessas sensações, ele conclui que "a emoção mais antiga e mais forte da humanidade é o medo, e o tipo de medo mais antigo e mais poderoso é o medo do desconhecido".

O medo não tem origem na vida adulta, como podem pensar alguns, mas na mais tenra idade, na infância, quando as crianças, como os primitivos, convivendo com o ambiente que as rodeia, têm a tendência a desenvolver medo daquilo que não lhes é familiar: o escuro, ficar sozinhas ou coisas e pessoas estranhas. Quando adultos, os homens tendem a superar esses traumas, porém movidos por impulsos hereditários, "sempre temerão ante a ideia dos mundos ocultos e insondáveis de existência singular" (LOVECRAFT, 2007, p.13).

Os escritores com grande imaginação se aproveitam dessa fragilidade humana e, nessa seara fértil, fazem brotar o que Lovecraft (2007, p.16) designa de "literatura do cósmico", uma ficção que tem existido de modo vigoroso, impulsionando gerações 
de escritores. Mesmo os mais avessos a esse estilo, em algum momento, tendem a produzir algo, mesmo que isoladamente, como forma de descarregar seus rompantes quiméricos. A essa criação do medo cósmico em seu sentido mais puro, ele denomina de "literatura de terror" cuja natureza assim se expressa:

uma certa atmosfera inexplicável e empolgante de pavor de forças externas desconhecidas precisa estar presente; e deve haver um indício, expresso com seriedade e dignidade condizentes com o tema, daquela mais terrível concepção do cérebro humano - uma suspensão ou derrota maligna e particular daquelas leis fixas da natureza que são nossa única salvaguarda contra os assaltos do caos e dos demônios dos espaços insondáveis. (LOVECRAFT, 2007, p.17)

Com uma ligação muito forte às emoções primitivas, as histórias de terror são tão antigas quanto a imaginação humana. Por isso, Lovecraft (2007) acredita que o "terror cósmico" aparece como fonte de inspiração no folclore mais primitivo, sendo encontrados traços desse medo transcendental nas baladas, lendas e escritos antigos, passando pela literatura clássica até a era moderna, e diríamos até os dias atuais. A Idade Média, por exemplo, conhecida como a Era das Trevas, não precisou de muito esforço para deixar um grande legado nesse campo, com suas histórias de bruxas e demônios necrófagos. Lovecraft (2007) concorda que a história fantástica típica da literatura nasceu no século XVIII e que $O$ castelo de Otranto (1764) serviu de inspiração para os criadores do terror cósmico, estimulando o crescimento de uma escola do Gótico. Todavia, na sua opinião, uma linhagem de verdadeiros representantes desse gênero só se estabelece no século XIX, começando com Poe. 
Por ter mais que assassinatos secretos, ossos ensanguentados, ou vultos cobertos com lençóis arrastando correntes, a "literatura de terror" puro, no dizer de Lovecraft, distingue-se em essência do horror, do qual nos ocupamos agora. King (1983, p.25), autor consagrado pelas suas histórias de horror, sabe melhor que qualquer outro o que assusta o leitor. Para ele, as emoções de medo se dividem em três níveis: "o terror no topo, o horror abaixo dele, e mais abaixo de tudo, a golfada de repulsa". 9 Se por um lado, ele reconhece essas distinções por elas serem úteis na leitura de uma obra, por outro, prefere evitar preferências por uma em detrimento das outras, baseado na ideia de que o efeito de uma é, de alguma maneira, melhor do que o das outras. Ademais, ele concebe o terror como "a mais refinada emoção"10 (p.21 - grifos nossos) e o horror como uma "emoção do medo subjacente ao terror, uma emoção que é um pouco menos refinada, porque não é totalmente da mente. O horror também invoca uma reação física ao nos mostrar algo que está fisicamente errado"11 (p.22).

Ele esclarece que se o escritor percebe que não vai ser capaz de

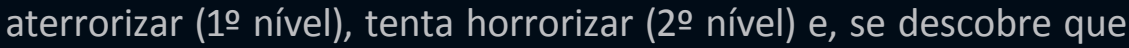
não vai conseguir horrorizar, apela para o horror explícito, repulsivo (3ํ nível). Quando pensa em terror, vem à sua mente o som contínuo do batimento cardíaco do velho em "The tell-tale heart" (1843), de Poe: "Era um som baixo, maçante, rápido - muito mais como um som que um relógio faz quando envolto em algodão."12 (p.559 -

9 Terror on top, horror below it, and lowest al all, the gag reflex of revulsion.

10 the finest emotion

11 Emotion of fear that underlies terror, an emotion which is slightly less fine, because is not entirely of the mind. Horror also invites a physical reaction by showing us something which is physically wrong.

12 It was a low, dull, quick sound - much such a sound as a watch makes when enveloped in cotton. 
grifos do autor).$^{13} \mathrm{O}$ efeito de terror é aí atingido na medida em que o leitor é levado a acreditar que o assassinato cometido por pura maldade é fruto da loucura do narrador e não de sua capacidade de cometer um ato perfeito em pleno vigor de sua sanidade. Já o horror lhe faz pensar no conto "Slime", do livro Nine horrors and a dream (1958), de Joseph P. Brennan, no qual a coisa amorfa, porém concreta, envolve o corpo de um cachorro ganindo. Em suma, os dois gêneros têm certos laços ao lidarem com o mais básico das histórias do medo: segredos inconfessáveis e coisas não ditas.

Reconhecendo que não há tantas temáticas a serem seguidas, porque a esfera do sobrenatural é estreita e escassa diante do grande escopo da literatura em geral, King (1983) nomina o Vampiro, o Lobisomem, a Criatura Inominável e o Fantasma como as quatro personagens principais da narrativa de horror. Segundo ele, esse tipo de ficção retorna à tensão apolínea e dionisíaca existente em toda ficção de terror, ou seja, o mal convivendo com o bem. Desses quatro arquétipos, o fantasma é o mais potente, porque é a parte principal daquele complexo mítico que todos devem se banhar, e consegue adotar, no final, todas as motivações e, talvez até mesmo, a alma daqueles que os veem. Para os propósitos do romance de horror, o fantasma deve ser malvado e o que nos faz retomar o conflito dionisíaco-apolíneo.

Segundo King (1983, p.62-63), a ficção do medo pode ser dividida em três categorias: a) as que lidam com o "mal interior" (The strange case of Dr. Jekyll and Mr Hyde), resultante de um desejo próprio livre e consciente - uma decisão consciente de fazer o mal;

13 Todas as citações dos contos de Poe deste trabalho são retiradas de POE, Edgar Allan. Poetry, tales, and selected essays. New York: The Library of America, 1996a. Deste ponto em diante, limitar-nos-emos a indicar os números das páginas. 
b) as que operam com o "mal exterior" (Dracula), em que o horror é predestinado, vindo de fora como o estrondo de um trovão; c) aquelas nas quais é impossível distinguir esses dois mundos (Ghost Story). Ele alerta que é exatamente esse mistério a respeito de onde está surgindo o mal que diferencia o bom do excelente e reconhece que na tentativa de reproduzir esse paradoxo, a maioria dos romances só consegue produzir uma confusão. Como exemplos dessa classe, cita Lovers living, lovers dead (1981), de Richard Lortz. llustrando a primeira categoria, mais uma vez, é tomado pela lembrança de Poe ao declarar que "talvez a melhor história de mal interior já escrita seja 'O coração delator', de Poe”"14.

Na concepção de King (1983), o que a mente é capaz de imaginar, estimulada por si só, é o que faz a quintessência das histórias de terror ao passo que o horror se realiza com o que os olhos veem. Tanto que David Punter (2009, p.245) assegura que o horror nos pega pelo choque e surpresa e "está 'na cara', ao passo que o terror consiste numa certa retenção da ocorrência do medo". ${ }^{15}$ Por isso, inclui mutilação de pessoas, possessões demoníacas, vampirismo, homens se transformando em lobisomens, necrofagia, sexo, violência, medo covarde, mortes gratuitas, sangue excessivo, entranhas e vísceras expostas, coisas gelatinosas e aracnídeas se espalhando de modo apelativo, cujo efeito é a repulsa e o principal objetivo é apavorar plateias. A escrita de Fred Botting (2009, p.192) corrobora essa configuração ao atestar que estando "ligado aos sentimentos de repulsa, nojo e repugnância, o horror induz a estados de tremor ou paralisia, à

14 Perhaps the best tale of inside evil ever written is Poe's "The tell-tale heart".

15 [It] is "in your face", whereas terror consorts with a certain withholding of the occasion of fear. 
perda de faculdades, particularmente, a consciência e a expressão, ou a impotência física e confusão mental. ${ }^{16}$

Assistindo a uma película de horror, o público geme, enquanto que diante de cenas de terror, os gritos são inevitáveis. King (1983) exemplifica essa assertiva dizendo que nas apavorantes cenas de Alien (1979), de Ridley Scott, a plateia parece mais propensa a gemer de repulsa do que de gritar de terror. Ao contrário dos filmes de terror que exigem um nível de refinamento, os de horror não são sofisticados, e são voltados para um público menos exigente que está continuamente disposto a dar uma olhada num gato morto, ou num corpo estrebuchando no chão, ou em qualquer coisa horrível que lhe faça quase golfar na sala do cinema.

Por intermédio do terror e horror, o Gótico alcança efeito, em grande escala, devido ao fato de estar ligado a outro modo de representação do qual não consegue se dissociar: o grotesco. Segundo Mikhail Bakhtin (2008), essa tendência oitocentista, como método de construção de imagens, procede de uma época muito antiga, levando-nos a crer que o fenômeno é mais antigo que o próprio nome.

O grotesco está presente em todos os povos, desde a mitologia e a arte arcaica, passando pela arte pré-histórica, dos gregos e romanos, até a época clássica, período em que foi excluído da arte oficial, mas continuou vivendo e desenvolvendo-se em certos domínios "inferiores" não cômicos. Essa tradição clássica não deu ao tipo de imagem grotesca uma denominação geral, reconhecendo-a pela teoria, nem lhe atribuiu um sentido preciso. Bakhtin (2008, 16 Bound up with feelings of revulsion, disgust and loathing, horror induces states of shuddering or paralysis, the loss of one's faculties, particularly consciousness and speech, ora general physical powerlessness and mental confusion. 
p.28) reforça que "o florescimento do realismo grotesco é o sistema de imagens da cultura cômica popular da Idade Média e o seu apogeu é a literatura do Renascimento".

O aparecimento do termo "grotesco" se dá nos fins do século XV, quando escavações em Roma, nos subterrâneos das Termas de Tito, encontram um tipo de pintura ornamental antiga até então desconhecido. Conforme o Etymology dictionary, recebeu o nome de grottesca, derivado do seu substantivo italiano grotta (gruta). Essa pintura era a representação de figuras fantásticas das formas vegetais, animais e humanas que se confundiam entre si, de modo que não se podiam distinguir fronteiras entre esses reinos. Na verdade, essas regiões limítrofes no grotesco eram superadas de maneira que o movimento das pinturas deixava de ser o de formas completamente acabadas. Havia um inacabamento da existência, expressa por uma liberdade e uma leveza excepcional da fantasia artística.

Inicialmente, o uso desse nome inédito, designando o que se acreditava ser um fenômeno novo, é restrito. E, por quase três séculos, a ampliação do vocábulo realizou-se muito lentamente, sem uma consciência teórica clara acerca da originalidade e da unidade do mundo grotesco. Bakhtin (2008) esclarece que uma compreensão mais profunda e ampla da palavra só aparece na segunda metade do século XVIII. Em 1788, o crítico alemão Flögel publica sua História do cômico-grotesco, em que não define nem delimita o termo, nem do ponto de vista histórico nem do ponto de vista sistemático. Ele qualifica de grotesco "tudo o que se aparta sensivelmente das regras estéticas correntes, tudo que contém um 
elemento corporal e material nitidamente marcado e exagerado" (FLÖGEL, Apud BAKHTIN, 2008, p.31) ${ }^{17}$.

Hugo (1802-1885), no "Prefácio" ao seu Cromwell (2010, p.30), informa que "o grotesco antigo é tímido, e que procura sempre esconder-se. Sente-se que não está no seu terreno, porque não está na sua natureza. Dissimula-se o mais que pode". Ele explica que alguns seres mitológicos são apenas disformes no seu aspecto exterior, sendo horrendos mais por seus atributos que por seus traços e, por vezes, a literatura antiga fazia esforço para disfarçar a deformidade. Ao contrário, entre os Modernos, o grotesco tem um enorme papel e está em toda parte, criando, de um lado, o disforme e o horrível e, de outro, o cômico e o bufo: "[...] é da fecunda união do tipo grotesco com o tipo sublime que nasce o gênio moderno, tão complexo, tão variado nas suas formas, tão inesgotável nas suas criações, e nisto bem oposto à uniforme simplicidade do gênio antigo". A partir desse ponto de vista é que ele estabelece a radical e real diferença entre a literatura antiga e moderna, elegendo o grotesco como "a mais rica fonte que a natureza pode abrir à arte".

Hugo reconhece que, apesar de ter suas ideias rebatidas pela crítica de seu tempo, o advento e o avanço do grotesco na era moderna é um aprendizado curioso e chega a sugerir que fosse feito um estudo mais extenso sobre o seu emprego nas artes. No século seguinte, Kayser (1906-1960), um pesquisador alemão não menos interessado nesse tópico, atende ao pedido do 
ensaísta francês ao lançar uma densa pesquisa, o livro O grotesco. Discutindo o grotesco no Romantismo, Kayser $(2003)^{18}$ atesta que é neste período que há as mais importantes exposições das ideias estéticas acerca desse estilo, de modo que o conceito passa por longas discussões e tende a avançar para o centro. Tendo por base as declarações de Friedrich Schlegel em uma resenha crítica de 1797, Kayser (2003) diz que o termo grotesco era empregado no mesmo sentido de arabesco e essa tendência não era corrente só na Alemanha, mas difundia-se entre os que se atreviam a conceituar o termo. De modo geral, o arabesco era tido como a forma mais antiga e primitiva de expressão da fantasia humana e era "usado inteiramente como sinônimo de 'grotesco'" (KAYSER, 2003, p.55), apesar de relegado a um patamar inferior.

Ele comenta que Walter Scott (1771-1832), em 1827, em uma resenha das novelas de Hoffmann (1776-1822), acaba por dar uma definição desse estilo ao escrever que o grotesco na obra do escritor alemão se assemelhava em parte ao arabesco na pintura, por empregar monstros disformes, exibir uma ilimitada fertilidade de fantasia e usar um exuberante contraste em todas as múltiplas e variadas formas. Kayser, fazendo uma leitura de algumas obras que lhes parecem grotescas, enumera muitos dos elementos que são essenciais nessas ficções:

a mescla do heterogêneo, a confusão, o fantástico, e é possível achar nelas [histórias grotescas] até mesmo algo como o estranhamento do mundo. Mas falta uma coisa: o caráter insondável, abismal, o interveniente horror em face das ordens em fragmentação. (2003, p.56 - grifos nossos) 
Partindo do exame de alguns contos de Poe, vemos que ele, conhecedor desses elementos, domina o gênero ao produzir cenas grotescas das mais elaboradas e tem consciência de sua eficácia como provocador de fortes impressões no leitor. Observa-se, ainda, que sabedor das ideias correntes, com muita perspicácia, ele as absorve, une às suas próprias concepções e consegue usar a seu modo as inesgotáveis possibilidades desse tipo de representação em suas criações.

Partindo do princípio que as formas literárias se mesclam, encontrando-se dificilmente puros os gêneros, é preciso verificar em que grau e em que condições o texto narrativo e o fílmico, eleitos como objetos de estudo deste artigo, possuem o terror, o horror e o grotesco como traços do gótico. Para proceder às análises, procuremos entender, primeiramente, o conto do qual é originário, iniciando com a sua fábula.

A narrativa do conto centra-se na rivalidade entre duas famílias de linhagem nobre: Berlifitzing e Metzengerstein. Wilhelm Von Berlifitzing é um velho conde de saúde fraca cuja vida é devotada à paixão aos cavalos e à caça. Frederick de Metzengerstein, um jovem barão, aos dezoito anos de idade, é o único herdeiro de volumosa fortuna. Após a perda prematura dos pais, ele passa a exibir um comportamento particularmente cruel, e tem os dias regados a orgias, atrocidades e mesquinharias. Certa noite, o estábulo do conde pega fogo e ele morre tentando salvar os animais. Os indícios levam a crer que o crime foi premeditado pelo barão. Na mesma noite, um estranho cavalo aparece no seu castelo, tomado por ele como propriedade. Desde então, o comportamento do jovem sofre sensível alteração, tornando- 
se uma pessoa solitária cujo único companheiro é o cavalo. Em uma noite tempestuosa, após Metzengerstein acordar e sair cavalgando em direção à floresta, seu castelo pega fogo. Quando ele retorna, sem o domínio do animal, é guiado diretamente para as chamas abrasadoras. À morte do cavalo e do cavaleiro e à destruição do castelo se ergue uma nuvem de fumaça em forma de um enorme cavalo.

A opinião de Arthur Hobson Quinn (1998) a respeito desse conto é esclarecedora: "Já nesta primeira história a unidade de construção e de tom, a sugestão magistral do sobrenatural, a preservação do suspense e a manipulação do clímax - muitas das grandes qualidades de Poe - estão em 'Metzengerstein'"19 (p.192). Lembrando que esse é o primeiro conto publicado por Poe, concordamos com Quinn, principalmente, se pensarmos que a "unidade de construção e de tom" está diretamente ligada ao "efeito" defendido por ele como o ponto de partida, a base da gênese de toda composição poética ou prosaica.

Fisher (2006), em seu artigo "Poe and the Gothic tradition", escreve que esse conto pode ser lido quase como se fosse uma enciclopédia do horror sobrenatural "alemão". Entretanto, alerta que qualquer que seja a quantidade de "germanismo" aí presente, ele se mantém como um importante barômetro das subsequentes realizações de Poe na ficção gótica, porque a sua atenção para a unidade de impressão ou efeito como a mola mestra da arte em narrativas curtas já se mostra em evidência. E argumenta que "[...] para um trabalho de aprendiz, o que pode facilmente trair seus 19 Already in this first story the unity of construction and of tone, the masterly suggestion of the supernatural, the preservation of suspense, and the handling of the climax - many of the great Poe quality - these are in "Metzengerstein". 
modelos, ele ['Metzengerstein'] demonstra a sofisticação de seu autor $^{20}$ (FISHER, 2006, p.80).

Visando ao terror como principal procedimento de representação do Gótico, Poe cria uma história ambientada em um castelo medieval, na remota Hungria, cujas personagens são movidas por um ódio hereditário que perdura por séculos. Como estratégia associada, a trama envolve o sobrenatural: uma tapeçaria misteriosamente animada em vez de um retrato mal-assombrado, um enorme cavalo sobrenatural cor de fogo - a metempsicose do velho conde Berlifitzing - e um jovem afligido por uma maldição que recai sobre a sua família. A rápida sucessão de acontecimentos, juntamente com o mistério crescente que cada um dispara, acrescenta-se aos elementos de angústia e fatalidade que pairam em torno do protagonista.

Quando Quinn (1998) fala desse conto, deixa de mencionar a construção das personagens como outra das grandes qualidades de Poe. Utilizando-se dos ornamentos da ficção gótica, o seu primeiro protagonista é o protótipo das personagens que viriam a povoar a maioria de suas histórias: raramente americanas, de linhagem antiga, são representação da aristocracia decadente; apesar de eruditas e dotadas, estão em crise e são atormentadas pelo passado e condenadas pelo destino, como Roderick Usher e Madeline; ou destroem a si mesmas, como William Wilson, Toby Dammit e o próprio Frederick de Metzengerstein. Restringindonos não somente aos contos policiais, mas à totalidade de suas narrativas, somos levados a concordar com Fisher (2006, p.87) que

20 [...] for an apprentice work, which might readily betray its models, it demonstrates its author's sophistication. 
"quase todas as histórias de Poe, de alguma maneira, podem ser categorizadas como histórias de crime, quer crime contra o outro, quer contra si próprio"21.

A cena final, com o fogo abrasante tomando conta do castelo, tece um espetáculo gótico na medida em que põe em cena a negrura da "fumaça" em contraste com a luminosidade do "clarão de luz", revelando a "sofisticação" de seu autor, aludida por Fisher (2006). Os efeitos aqui atingem proporções onomatopaicas se visualizarmos a primeira passagem na qual praticamente se podem ouvir o assobio do vento e o estalido do castelo, e ver as chamas subindo. Ainda, está presente o sobrenatural como constituinte do Gótico, pois o fogo começa sem explicação natural, conforme esclarecimento anterior, movido por forças inexplicáveis, ou por um pavor de forças externas desconhecidas. A utilização desse recurso, criando uma atmosfera na qual "o critério final de autencidade não é a harmonização de um enredo, mas a criação de uma determinada sensação" (LOVECRAFT, 2007, p.17), enquadra esse conto na categoria das histórias genuínas de terror cósmico em seu sentido mais puro.

Por fim, observa-se que o terror persegue as personagens na luta pelo poder, levando-as à decadência. Talvez pela metempsicose os Metzengerstein e os Berlifitzing possam encontrar paz e prosperidade, mas essa é apenas uma hipótese dada à abertura do desfecho. Como o diretor Vadim retrata essas personagens é a nossa preocupação nas páginas seguintes, iniciando com um apanhado resumido do enredo do segmento.

21 Nearly all of Poe's tales, however, may be categorized as crime stories, whether the crime be against another or against the self. 
A condessa Frederique de Metzengerstein, uma jovem de vinte e dois anos de idade, após herdar a fortuna da família, vive uma vida de promiscuidade sexual e crueldade. Ela tem como vizinho o barão Wilhelm de Berlifitzing, seu primo, um jovem absorto pelo amor aos cavalos e à caça. Eles não aprenderam a cultivar estreitas relações familiares devido a uma antiga rivalidade de famílias. Certo dia, num passeio pelos arredores, Frederique cai em uma armadilha para animais e é libertada pelo primo. Ela tenta conquistá-lo, porém ele não cede aos seus encantos. Ela não aceita o fato de ter sido rejeitada e, em desforra, manda atear fogo no estábulo dele. Pouco tempo depois, fica sabendo que Wilhelm morreu, tentando salvar os animais. Em seguida, um cavalo que supostamente escapou das chamas aparece no seu castelo. Os servos da condessa têm dificuldade de pegar o animal e cabe a ela a missão de dominálo. Desde então, há uma sensível mudança no comportamento da jovem: ela passa horas a fio na companhia do animal, tendo-o como único companheiro. Certo dia, alucinada, sai para um passeio noturno como de costume e é conduzida pelo cavalo para uma área queimada. Nesse cenário terrificante, ela tem o mesmo fim trágico de seu primo.

Esse breve resumo sinaliza que a adaptação segue a mesma linha gótica do conto ao ser ambientado em um castelo feudal, ao preservar a temática da metempsicose e, principalmente, por manter em cena uma personagem que é dominada pelo instinto de perversidade. Contudo, é substancial o deslocamento de papeis das personagens: o velho conde do texto adaptado passa a ser o jovem barão Wilhelm de Berlifitzing ao passo que o barão Metzengerstein torna-se a jovem condessa Frederique na adaptação. 
Segundo Linda Hutcheon (2011, p.33), sendo as personagens essenciais aos efeitos retóricos e estéticos de textos narrativos e performáticos, no processo de adaptação, "é claro, também podem ser transportadas de um texto a outro" e, como os outros elementos da história, são passíveis de sofrer alterações. Como foco da versão cinematográfica, as personagens protagonistas, além de vizinhos, são primos, mas não mantêm nenhuma familiaridade devido à secular discórdia entre as famílias. A relação entre eles, similarmente ao conto, permanece no campo do ódio recíproco e, na visão de Vadim, as desavenças são agravadas pela rejeição decorrente da paixão não correspondida de Frederique por Wilhelm. Esse sentimento marca a protagonista em profundidade, tanto que a ação de descaso dele insiste em retornar-lhe à memória e, mesmo depois de sua morte, sua imagem sempre volta a lhe perturbar repetidas vezes e envolta em um eco dramático.

Vejamos a entrada do segmento. Assim que cessam os créditos do filme, o espectador é surpreendido com uma cena que aparece abruptamente. O plongée ${ }^{22}$ distante que termina em plongée próximo exibe o corpo de um jovem caído de costas no chão, com um ferimento na testa. Inicialmente, esse modo brusco de apresentação leva-nos a pensar em uma ruptura ou falta de conexão com a abertura do filme, porém numa minudente leitura, nota-se que a cena mantém estreita ligação com a epígrafe que toma de empréstimo a introdução do conto "Horror e fatalidade

22 Marcel Martin (1990, p.41) identifica os ângulos de filmagem: o plongée, no qual a câmara se posiciona acima do seu objecto que é visto em ângulo superior, tende a "apequenar o indivíduo, a esmagá-lo moralmente, rebaixando-o"; o contre-plongée, no qual a câmara fica abaixo do objeto, fazendo com que o espectador veja a cena de baixo para cima, dá geralmente uma impressão de "superioridade, exaltação e triunfo, pois faz crescer os indivíduos e tende a torná-los magníficos". 
têm sido disseminados em todos os tempos. Por que, então, datar a história que tenho de contar?"23. Ainda, funciona como uma ilustração da mesma, na medida em que uma gota de sangue na camisa branca na altura do coração e uma poça de sangue acima da cabeça do jovem, filmados em primeiro plano ${ }^{24}$, completam a cena e reforçam o horror anunciado.

O segmento pode ser dividido em duas partes. A primeira com predominância de cenas em espaços abertos, e a segunda na qual são privilegiados os espaços fechados. Aquela indica o ambiente festivo no qual vive a personagem, mostrando o seu lado extrovertido ao gozar de total liberdade, em todos os sentidos. Esta reflete a introspecção da personagem, ou seja, destaca a alteração de sua conduta, depois da morte do primo, quando ela se torna, a exemplo do conto, uma personagem reclusa, ausente do convívio social.

Em linhas gerais, o segmento prima pelo plano geral (predominante na primeira parte), com belas cenas nas quais são realçados a praia, o mar, os campos, os castelos, as montanhas e os arredores, dando mais relevo à paisagem que à ação. Esse tipo de enquadramento dá leveza, ressalta o primoroso trabalho de fotografia de Claude Renoir e revela o perfil do diretor. Num

23 Horror and fatality have been stalking abroad in all ages. Why then give a date to the story I have to tell? (2003, p.54)

$24 \mathrm{Na}$ nomenclatura técnica cinematográfica, o "plano" diz respeito à distância entre a câmera e o objeto filmado. Seguindo a terminologia utilizada por Antonio Costa (1987), temos: o "plano geral" que foca uma paisagem ou um cenário na sua totalidade; o "plano de conjunto" que capta os espaços interiores, mostrando cenários completos e grupo de personagens; o "plano de meio-conjunto" ou "plano médio" que revela um trecho do ambiente, dando destaque à figura humana, sem isolá-la; o "plano americano" que isola uma personagem, sendo filmada dos joelhos para cima; o "primeiro plano" que exibe a figura humana de meio busto para cima; o "primeiríssimo plano" que enquadra apenas o rosto. 
primeiro momento, pode-se pensar que as formosas paisagens destoam da linha gótica que privilegia ambientes isolados e atmosferas penumbrosas e soturnas. Todavia, numa leitura mais atenta, observa-se que o contraponto entre a beleza da paisagem e o horror das cenas com as personagens provoca mais impacto no espectador que não espera esse contraste.

Outro aspecto marcante na produção de Vadim é o apelo às cores, que também fogem do padrão acinzentado e escurecido característico das películas góticas. Gérard Betton (1987, p.58) escreve que "a cor impõe uma nuance 'decorativa' à imagem fílmica", por isso é considerada contraindicada para alguns assuntos violentos como guerra, policiais e o terror. No entanto, verifica-se na narrativa fílmica uma riqueza de cores, podendo visualmente ser dividida em duas partes: na primeira, há as dominantes azul (céu, lago, mar) e verde (montanhas, floresta); na segunda, uma dominante vermelha (fogo).

Na primeira parte, uma progressão arrasta-nos à medida que a tensão dramática cresce de uma paisagem verdejante, ao lado do colorido esfuziante do interior do castelo, a um vermelho alaranjado, na segunda parte, com as cavalariças de Wilhelm e a tapeçaria em chamas. No final, essa progressão é bem nítida. Aparecem gramíneas viçosas que se consomem com o fogo abrasador: à proporção que os campos vão pegando fogo, Frederique cavalga sobre eles e caminha para a morte. Nessa mudança de paisagem, a cor tem um papel relevante visto que o diretor explora as tonalidades "mais frias" e "mais quentes", visando o contraponto com o conteúdo dramático das imagens. 
As cores são trabalhadas e escolhidas em função daquilo que o diretor quer exprimir. Na primeira parte, as tonalidades "mais frias" (natureza) se opõem às tonalidades "mais quentes" da exaltação das cenas de banquete e orgias do interior do castelo. Na segunda parte, as relações cromáticas criam novas analogias. As tonalidades "quentes" as quais estão associadas à luxúria, na primeira parte, estão ligadas aos sentimentos de vingança da protagonista e aos seus dramas. Isso evidencia que bem mais importante que o uso das cores é o seu dinamismo, suas relações de contiguidade e sua transformação gradual em outras cores.

A respeito da personagem protagonista, a condessa Frederique de Metzengerstein, encontramo-la em diversos lugares, aparentemente sem conexão um com o outro, o que, intuitivamente, nos levaria a pensar em sequências soltas, desconexas, por formarem blocos isolados. Distanciando-se do cinema clássico que "pretendia esconder o seu caráter de linguagem e apresentar-se como se fosse realidade" (BERNARDET, 2000, p.106), reconhecemos que essa é uma estratégia intencional do diretor de provocar uma reação no espectador por meio de imagens cortadas, com ritmo quebrado. Aproximando-se do princípio de que "um filme é uma sucessão de pedaços de tempo e de pedaços de espaço" (BURCH, 2006, p.24 - grifos do autor), Vadim utiliza a quebra entre uma sequência e outra para justamente chamar atenção sobre a personalidade fragmentada da personagem. Este tipo de estrutura narrativa fraturada inicia-se nos anos 60 do século XX (por exemplo, o filme Pocilga (1969), de Pasolini) e funciona, no presente caso, como variações do jogo de horror e sadismo versus harmonia e magnificência da natureza. 
A investigação levada a cabo até aqui nos orienta a inferir que o segmento de Vadim se constitui um bom exemplar de peça gótica pelo modo de reprodução da tradição da cultura popular medieval. Uma dessas manifestações é a do "princípio da vida material e corporal", conceito desenvolvido por Bakhtin (2008). Na sua acepção, esse princípio diz respeito às "imagens do corpo, da bebida, da comida, da satisfação de necessidades naturais, e da vida sexual" (BAKHTIN, 2008, p.16). Essas imagens são a herança da cultura cômica popular, de uma concepção estética da vida prática da cultura medieval que se diferencia das culturas clássicas posteriores. A esse tipo de manifestação comum na literatura medieval e renascentista, Bakhtin convenciona como "realismo grotesco" cujo traço marcante é "o rebaixamento, isto é, a transferência ao plano material e corporal, o da terra e do corpo na sua indissolúvel unidade, de tudo que é elevado, espiritual, ideal e abstrato" (2008, p.17 - grifo nosso). Nessa forma de expressão, o princípio material (comer, beber, necessidades naturais) e corporal (corpo, sexo) aparece sob a forma universal, festiva e utópica, ficando intimamente ligados. Nesse sentido, as palavras de Bakhtin são esclarecedoras:

O princípio material e corporal é percebido como universal e popular, e como tal opõe-se a toda separação das raízes materiais e corporais do mundo, a todo isolamento e confinamento em si mesmo, a todo caráter ideal abstrato, a toda pretensão de significação destacada e independente da terra e do corpo. (2008, p.17 grifos do autor).

Percebe-se enfatizado no "realismo grotesco" o elemento material e corporal como princípio positivo o qual está 
irremediavelmente atado a todos os aspectos da vida donde advém o seu caráter universal. Para explicar que o "rebaixamento" não tem uma apreciação negativa, Bakhtin (2008) assevera que a degradação do belo não possui um caráter formal ou relativo. No seu entendimento, o "alto" e o "baixo" são vistos sob uma perspectiva topográfica: no aspecto cósmico, o "alto" diz respeito ao céu e o "baixo", à terra; no sentido corporal, interligado com o anterior, a cabeça representa o "alto", e os órgãos genitais, o ventre e o traseiro equivalem ao "baixo". No segmento, não há cenas que mostrem a satisfação de necessidades fisiológicas, ficando tais funções no plano do subentendido. Em contrapartida, são exploradas cenas nas quais é exibida a abundância de comida, bebida e vida sexual, nas seguintes variações: incesto, lesbianismo, ménage à trois e orgias.

Não perdendo de vista a asseveração bakhtiniana no que concerne ao exagero do elemento material e corporal como fator positivo, examinemos essas variedades de opções sexuais com o intuito de descobrir a relação delas com o comportamento da protagonista. Uma mise-en-scène rica em detalhes apresenta as orgias (Figura 01): em uma enorme sala preparada para um banquete festivo doméstico, estão reunidas muitas pessoas nobres e serviçais, entre elas a anfitriã, Frederique, que passeia no meio delas. Não se ouvem vozes, somente uma música medieval e o riso generalizado dos convivas que completa a trilha sonora da sequência. A visão da movimentação fica por conta do plano de meio-conjunto que se encarrega de mostrar os convidados com taças na mão e a alegria coletiva. 


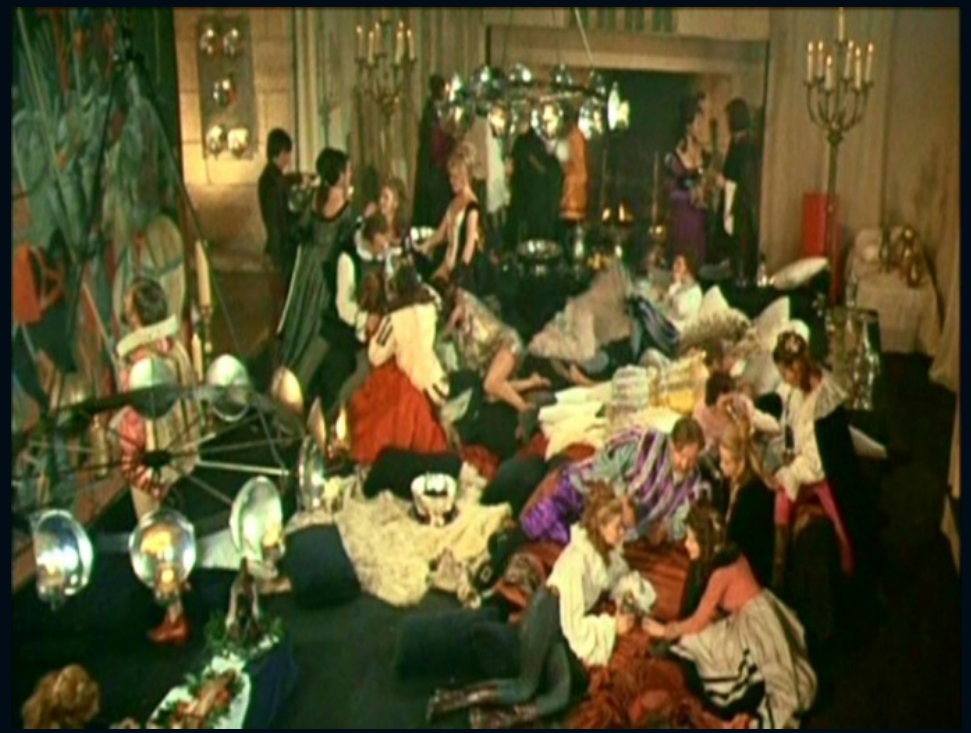

Figura 01: Orgia no castelo $\left(2003,10^{\prime} 03^{\prime \prime}\right)$

Georges Bataille, escritor francês, que no início do século XX despendeu grande esforço examinando o erotismo, constata que na orgia "o movimento da festa ganha essa força dissipadora que geralmente pede a negação de todos os limites (BATAILLE, 2004, p.175 - grifos nossos). Sendo cuidadosamente planejada pelo diretor, essa sequência enquadra pessoas trocando carícias e Frederique, sozinha, apreciando a devassidão coletiva. O mesmo autor explica que o erotismo necessita de um objeto do desejo, mas que na orgia esse objeto não se sobressai. A excitação sexual, neste caso, acontece por um movimento de todos, coletivo, e não é provocada por um elemento distinto. Por isso, a orgia se mantém para além do prazer individual. Isso explica o fato de estarem todos no mesmo ambiente, sendo excitados mutuamente, incluindo Frederique que, atuando como um voyeur, assiste, para a sua satisfação, às manifestações de sexualidade de outrem. Não é por 
acaso que a sequência idealizada por Vadim se aproxima das festas das Saturnais na quais as orgias, sem importar a desordem que elas introduziam, organizavam o erotismo além da sexualidade animal.

A festa não traz satisfação à protagonista. Frederique, em decorrência de seu amor libidinoso, que induz à precipitação e à inconstância, procura no primo um possível amante e investe com todo ardor nessa relação incestuosa. Tema estudado exaustivamente por Sigmund Freud $(1996$, p.35) leva-o a constatar que o incesto, relação sexual entre parentes consanguíneos, é preocupação para as sociedades desde o homem primitivo, porque um princípio de regras encara que até o mais distante grau de parentesco é impedimento absoluto para as relações sexuais. Ele crê que essa rejeição é "um produto da aversão que os seres humanos sentem pelos seus primitivos desejos incestuosos, hoje dominados pela repressão". Entendido dessa maneira, Frederique, ao manifestar desejo pelo primo, dá vazão aos impulsos mentais ocultos e, levada por uma tentação da fantasia, é mobilizada pela ação de laços inconscientes. Agindo assim, nos moldes das personagens góticas que põem em questionamento o senso corrente, ela demonstra ser uma personagem cética que não é guiada pelas normas de conduta geral.

A busca pelo prazer faz com que a protagonista procure outros tipos de parceiros, chegando a optar por uma relação homossexual, exibida em uma sequência rápida (Figura 02). Filmada com a câmera parada, em plano de meio-conjunto, rica em sensualidade, a temática do lesbianismo é tratada com muita delicadeza: sob o som de uma flauta doce, a condessa toma banho em uma banheira com outra mulher. Elas estão imersas na água de maneira a 
permitir apenas a visualização de seus colos e braços. Com gestos lascivos, elas se acariciam no rosto e nos seios, e se divertem com gracejos, deixando transparecer que a condessa tem seus caprichos encorajados, mesmo os mais devassos.

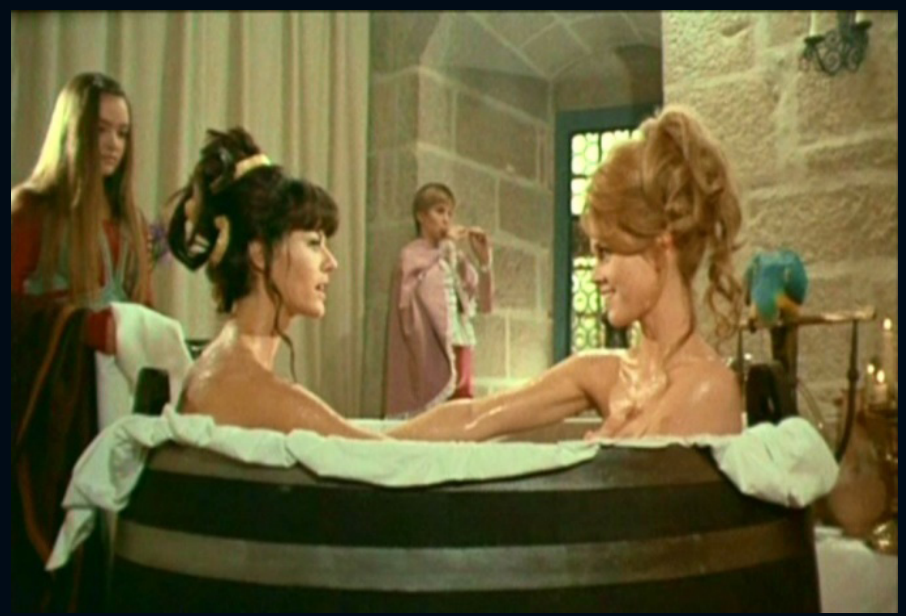

Figura 02: Carícias na banheira (2003, $\left.8^{\prime} 21^{\prime \prime}\right)$

A não realização de Frederique a leva a outras experiências como ménage à trois, reproduzida em uma sequência de curta duração (Figura 03): o primeiríssimo plano tem a atribuição de mostrar um filhote de felino sobre a cama, adornando o cenário preparado para mais uma aventura sexual de Frederique. Essa cena cuidadosamente planejada joga com as cores, pois o pelo colorido e brilhante do animal contrasta com o azul acetinado dos lençóis. A docilidade do filhote opõe-se semanticamente ao quadro de luxúria que viria a seguir. As vozes-off ${ }^{25}$ denunciam a entrada de 25 Sobre a voz no cinema, Mary Ann Doane (1983) faz distinção entre voz-off e vozover. A primeira refere-se a momentos nos quais ouvimos a voz de uma personagem que não é visível na tela, mas está presente no espaço da cena. Neste caso, "o filme, por meio de sequências anteriores ou por outros determinantes contextuais, afirma a 'presença' do personagem no espaço da cena, na diegese" (DOANE, 1983, p.462). A segunda emana de um corpo não presente no espaço cênico, sendo utilizada onde existe 
duas pessoas no recinto, sendo que a voz masculina diz que tem uma surpresa. Ao levantar os lençóis, um plongée médio revela a condessa que os aguarda para um momento de amor. Filmados sob um leve plongée, a condessa e o marquês, abraçados na cama, deixam entrever suas intenções ao puxar a mulher para a cama. No final da sequência, ela fica refém entre os dois amantes que tentam forçá-la ao ménage à trois.

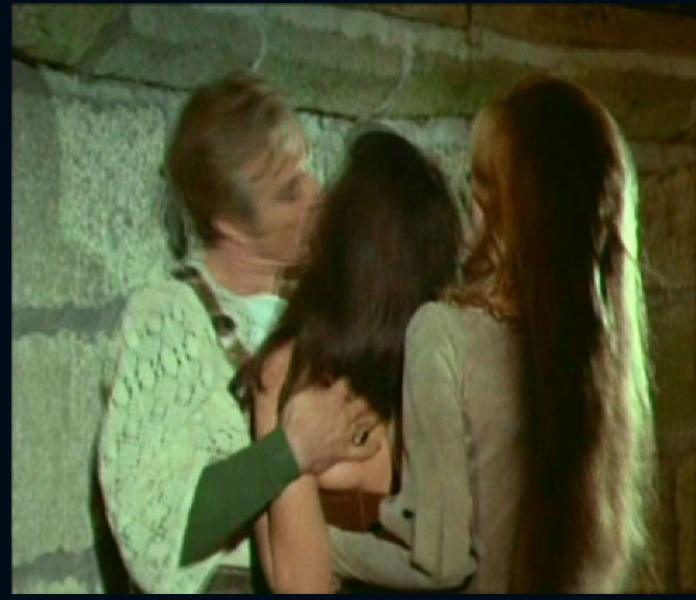

Figura 03: Ménage à trois (2003, 6’31")

Todas essas sequências servem para introduzir na fita ambientada em tempos medievais o Gótico feminino. Esse gênero começa a aparecer no cenário cinematográfico no início dos anos 1940, com o filme americano Rebecca (1940), de Alfred Hitchcock (1899-1980), uma versão do romance homônimo. Segundo Misha Kavka (2011), os filmes do Gótico feminino postulam uma protagonista feminina que é, simultaneamente, uma vítima e uma investidora de uma perseguição causada 
por preocupações sobre a sua sexualidade transgressora. A obsessão em si pode ser real ou simplesmente paranóica. O que é importante nesses filmes é que a linha entre o sobrenatural e o psicológico permanece permeável, com o resultado de que fantasmas devem igualmente ser lidos como manifestações psicológicas, enquanto medos paranóicos sempre sugerem a possibilidade de uma estranha materialização.

Para essa estudiosa, "a mulher no centro do Gótico feminino, então, está em uma encruzilhada entre a constrangida, mas respeitável normalidade doméstica, e a desviante, ou excessiva, sexualidade"26 (KAVKA, 2011, p.219-220). Seus atos de investidas, codificados como masculinos, muitas vezes estão prestes a levá-la ainda mais longe nos desvios, enquanto seu estatuto de vítima ameaça apagar a possibilidade de normalidade doméstica. Desse modo, Frederique, uma personagem enérgica, violenta, com excessos libidinosos, cujos desejos se situam no campo da liberdade, desmistifica a figura cultural da liberação sexual como mostruosidade. Ela está em consonância com a política sexual da década de 1940 até o início dos anos 1960, travada num ambiente social rigoroso e opressivo, cuja liberação é retratada com efervecência no cinema nesse período, alastrando-se até os anos 70.

O desfecho ilustra bem essa liberdade feminina. Conforme Don G. Smith (2003), nas cenas finais, as expressões faciais e reações físicas de Frederique são indiscutivelmente as de quem faz amor (Fig. 04). Acrescentando a esse raciocínio a ideia de que as suas vestes brancas transparentes e esvoaçantes aproximam-se mais 
das de uma noiva em núpcias, temos que o conjunto cenográfico causa o efeito intencionado pela película ao ressaltar, mais uma vez, o simbolismo sexual. Por fim, inevitavelmente, somos levados a conjecturar que as chamas as quais engolem a personagem são o fogo de sua libido, de maneira que a reprodução do gozo e prazer corrobora o espetáculo de horror.

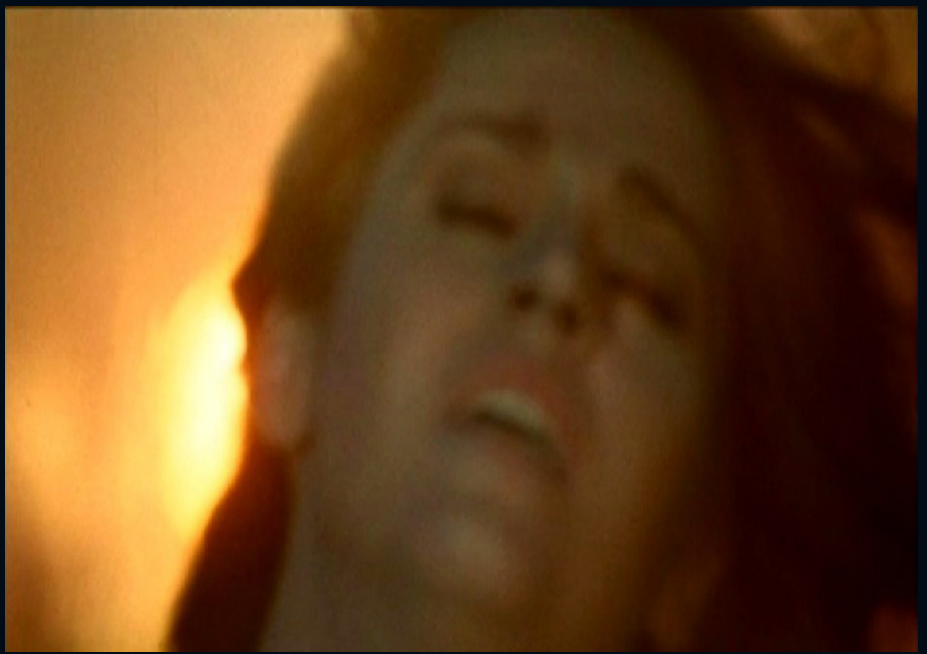

Figura 04: O êxtase de Frederique (2003, 38'25")

À guisa de conclusão, pode-se dizer que o diretor interpreta o conto à sua maneira, dando vida às personagens existentes ou criando outras, recuperando a fábula e ajustando o enredo, porém resgata as temáticas, de modo que faz uma imersão em Poe, conseguindo reter o significado do texto adaptado. Ademais, pode-se inferir que a produção fílmica conserva no modo visual a rica herança gótica de Poe, levando-nos a crer que o seu goticismo consegue ser representado expressivamente no cinema, tendo sido preservada a marca de seu diretor nessa outra mídia. 


\section{REFERÊNCIAS}

BAKHTIN, Mikhail (2008). A cultura popular na Idade Média e no Renascimento: o contexto de François Rabelais. Yara Frateschi Viera (Trad.). Brasília: UNB. BATAILLE, Georges (2004). O erotismo. Cláudia Fares (Trad.). São Paulo: Arx. BERNARDET, Jean-Claude (2000). O que é o cinema. São Paulo: Brasiliense. BETTON, Gérard (1987). Estética do cinema. Marian Appenzeller (Trad.). São Paulo: Martins Fontes.

BOTTING, Fred (2009). Horror. In: MULVEY-ROBERTS, Marie (Ed.). The handbook to Gothic Literature. Basingstoke: Palgrave Macmillan, p.184-192.

BURCH, Noël (2006). Práxis do cinema. Marcelle Pithon e Regina Machado (Trad.). São Paulo: Perspectiva.

CLERY, E. J. (2011).The Genesis of "gothic" fiction. In: HOGLE, Jerrold E. The Cambridge companion to gothic fiction. Cambridge: Cambridge University Press, p.21-39.

COSTA, Antonio (1987). Compreender o cinema. Nilson Moulin Louzada (Trad.). Rio de Janeiro: Globo.

DICTIONARY OF LITERATURE (1999). New Lanark: Geddes \&Grosset Press.

DOANE, Mary Ann (1983). "A voz no cinema: a articulação de corpo e espaço". In: XAVIER, Ismail (Org.). A experiência do cinema. Luciano Figueiredo (Trad.). Rio de Janeiro: Graal/Embrafilmes, p.457-475.

ETYMOLOGY DICTIONARY (2014). In http://www.etymonline.com/. Acesso em 23. Out.2017.

FISHER, Benjamin F. (2006). "Poe and the Gothic tradition". In: HAYES, Kevin J. (Ed.). The Cambridge companion to EdgarAllan Poe. Edinburg: Cambridge, p.72-91. FREUD, Sigmund (1996). "O horror ao incesto". In: FREUD, Sigmund. Obras psicológicas completas de Sigmund Freud: edição standard brasileira. Jayme Salomão (Trad. e Org.). Rio de Janeiro: Imago, v.XIII, p.21-35.

HOGLE, Jerrold E (2011). "Introduction: the Gothic in western culture". In: HOGLE, Jerrold E. The Cambridge companion to gothic fiction. Cambridge: Cambridge University Press, p.01-20.

HUGO, Victor (2010). Do grotesco e do sublime: tradução do prefácio de Cromwell. Célia Berrettini (Trad.). São Paulo: Perspectiva. 
HUTCHEON, Linda (2011). Uma teoria da adaptação. André Cechinel (Trad.). Florianópolis: UFSC.

KAVKA, Misha (2011). "The gothic on screen". In: HOGLE, Jerrold E. The Cambridge companion to gothic fiction. Cambridge: Cambridge University Press, 2011, p.209-228.

KAYSER, Wolfgang (2003). O grotesco. J. Guinsburg (Trad.). São Paulo: Perspectiva. KING, Stephen (1983). Danse macabre. New York: Berkeley Books.

LOVECRAFT, H. P. (2007). O horror sobrenatural em literatura. Celso M (Trad.). Paciornik. São Paulo: Iluminuras.

MARTIN, Marcel (1990). A linguagem cinematográfica. Paulo Neves (Trad.). São Paulo: Brasiliense.

POE. Edgar Allan (1996a). Poetry, tales, and selected essays. New York: The Library of America.

. (1996b). "Preface - Tales of the grotesque and arabesque". In: POE, Edgar Allan. Poetry, tales, and selected essays. New York: The Library of America, p.129-130.

PUNTER, David (2009). "Terror". In: MULVEY-ROBERTS, Marie (Ed.). The handbook to Gothic Literature. Basingstoke: Palgrave Macmillan, 2009, p.243-249.

QUINN, Arthur Hobson (1998). Edgar Allan Poe: a critical biography. New York: Johns Hopkins.

SMITH, Don G. (2003). The Poe cinema: a critical filmography of theatrical releases based on the works of Edgar Allan Poe. North Carolina: McFarland \& Company.

VADIM, Roger (2003). “Metzengerstein” In: Histórias Extraordinárias. França: Films Marceau; Concinor; PeaCinematografica, 2003. DVD (41/121 min.), widescreen, colorido, legendado.

WALPOLE, Horace (1994). O castelo de Otranto. Alberto Alexandre Martins (Trad.). São Paulo: Nova Alexandria. 